\title{
Localisation of prostaglandin $\mathrm{F}_{2 \alpha}$ and $\mathrm{E}_{2}$ binding sites in the human eye
}

\author{
Toshihiko Matsuo, Max S Cynader
}

\begin{abstract}
Prostaglandin $F_{2 \alpha}$ reduces intraocular pressure possibly by increasing uveoscleral outflow. To further understand the mechanism of its action binding sites for prostaglandin $F_{2 \alpha}$ and, for comparison, prostaglandin $E_{2}$ were localised in sections of human cadaveric eyes using an in vitro ligand-binding technique and autoradiography. Specific binding sites for both prostaglandin $F_{2 \alpha}$ and $E_{2}$ were co-localised at a high level in the areas of the ciliary muscles and iris sphincter muscles, and at a lower level in the iris epithelium and the retina. The results suggest that prostaglandin $F_{2 \alpha}$ and also prostaglandin $E_{2}$, could modulate uveoscleral outflow by binding to their receptors located on the ciliary muscles and inducing their relaxation.
\end{abstract}

Prostaglandin $\mathrm{F}_{2 \alpha}$ and especially its more lipophilic prodrug prostaglandin $F_{2 \alpha^{-1}}$-isopropylester can reduce intraocular pressure (IOP) when applied topically to normal human volunteers ${ }^{123}$ and patients with glaucoma. ${ }^{45}$ Prostaglandin $F_{2 \alpha}$ isopropylester is a very promising drug for glaucoma treatment because it has a prolonged potent hypotensive effect in low doses and lacks serious subjective or objective side effects.

A working classification of prostanoid receptors for five naturally occurring prostaglandins has been proposed based on pharmacological studies in which the agonist potencies of naturally occurring prostaglandins as well as other synthetic agonists and antagonists were compared.$^{67}$ Receptors sensitive to thromboxane $A_{2}$, prostaglandin $D_{2}, E_{2}, F_{2 \alpha}$, and $I_{2}$ have been designated as TP, DP, EP, FP, and IP-receptors, respectively. The EP receptor can be further classified into three subtypes, called $\mathrm{EP}_{1}, \mathrm{EP}_{2}$, and $\mathrm{EP}_{3}$ receptors. ${ }^{89}$ The $\mathrm{EP}_{3}$ receptor has been shown to be involved in reduction of IOP in rabbits. ${ }^{11}{ }^{11}$ However it is not known which class of prostanoid receptors is involved in the pressure reduction for humans and where within human eyes the receptors for prostaglandin $F_{2 \alpha}$ are located.

There is evidence that prostaglandin $F_{2 \alpha}$ lowers IOP by increasing uveoscleral outflow in monkeys. ${ }^{12-14}$ In order to further understand the basic mechanism of its action it is crucial to reveal the localisation of binding sites (receptors) for prostaglandin $F_{2 \alpha}$ in the eye. It is also important to use human eyes since there are considerable anatomical and physiological differences between the eyes of different species, especially in the systems controlling aqueous humour outflow. ${ }^{15}$ In this study we localised binding sites for prostaglandin $F_{2 \alpha}$ and also for prostaglandin $E_{2}$ in human eye sections using an in vitro ligand binding technique and autoradiography:

\section{Materials and methods}

\section{PREPARATION OF HUMAN EYE SECTIONS}

Human cadaveric eyes were obtained within 24 hours after death from the Eye Bank of British Columbia. The eyes used in this study had no documented ocular diseases. They were frozen in isopentane cooled to $-80^{\circ} \mathrm{C}$ and stored at $-20^{\circ} \mathrm{C}$ until use. Sections of $20 \mu \mathrm{m}$ thickness were cut with a cryostat (Cambridge Instruments, Nussloch, Germany) and placed on glass slides coated with $1 \cdot 7 \%$ gelatin.

IN VITRO LIGAND BINDING AND AUTORADIOGRAPHY The sections were thawed at room temperature and preincubated in $50 \mathrm{mM}$ tris-hydrochloride buffer ( $\mathrm{pH} \mathrm{7.4)}$ containing $100 \mathrm{mM}$ sodium chloride, $3 \mathrm{mM}$ calcium chloride, and $5 \%$ (weight/volume) bovine serum albumin (BSA, Sigma, St Louis, MO, USA) for 60 minutes at room temperature. The sections were then incubated in the same buffer containing 10-20 nM of tritiated prostaglandin $\mathrm{F}_{2 \alpha}$ or $\mathrm{E}_{2}$ (Du Pont Canada, Mississauga, Ontario) for 90 minutes at room temperature, washed for 60 minutes in the ice-cold buffer containing $1 \% \mathrm{BSA}$, and finally dried in an air stream. The sections were then apposed to tritium-sensitive films (Hyperfilm ${ }^{-3} \mathrm{H}$ : Amersham Canada, Oakville, Ontario) for 8 weeks in the dark. Non-specific binding was determined by incubating sections in the buffer containing, in addition, $100 \mu \mathrm{M}$ unlabelled prostaglandin $F_{2 \alpha}$ or prostaglandin $E_{2}$ (Cayman Chemicals, Ann Arbor, MI, USA) as well as $10-20 \mathrm{nM}$ of a labelled ligand.

\section{Results}

Specific binding sites for both prostaglandin $F_{2 \alpha}$ and $E_{2}$ were co-localised in the areas of the ciliary muscles and iris sphincter muscles at a high level, and also in the iris epithelium and the retina at a lower level as shown in Figures 1 and 2. The lens structure showed apparently moderate levels of the binding for both prostaglandins, which were not distinctive compared with levels of the corresponding non-specific binding. The results were reproducible in three eyes from three different individuals: a 60 -yearold man who died of cerebral infarction, a 70year-old woman who died of myocardial infarction, and a 52-year-old woman who died of colon cancer.

The binding of $20 \mathrm{nM}$ tritiated prostaglandin $F_{2 \alpha}$ in all of the areas could be totally displaced by 


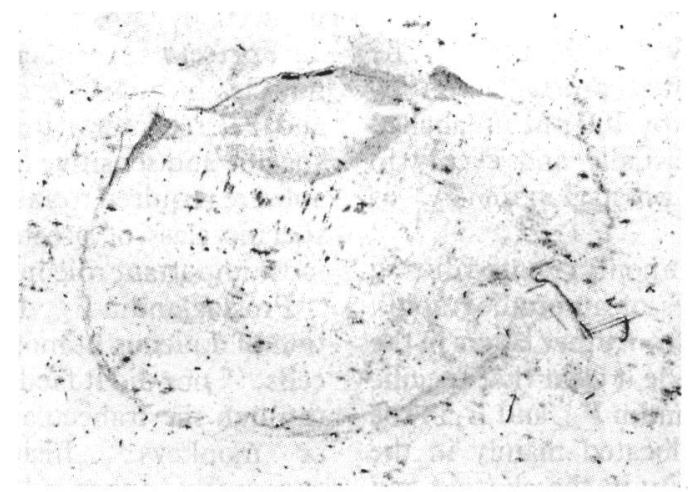

Fig $1 A$

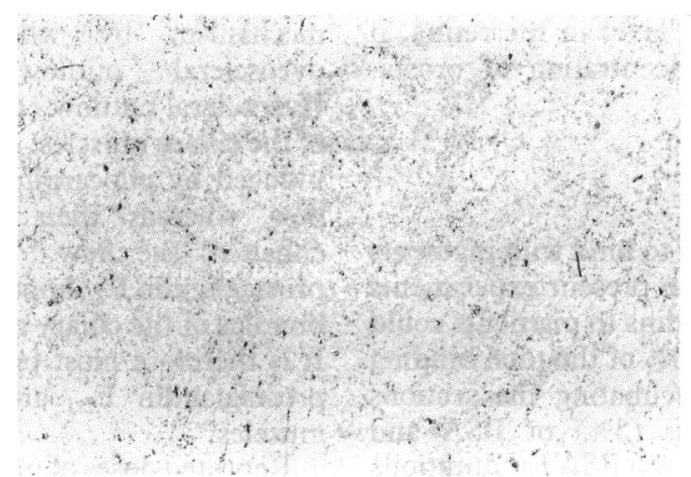

Fig $1 B$

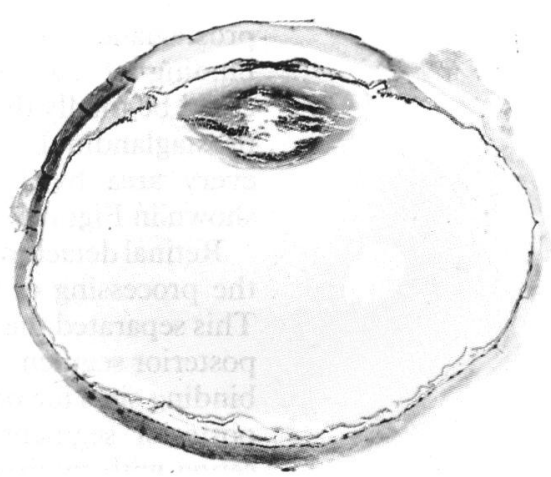

Fig $1 C$

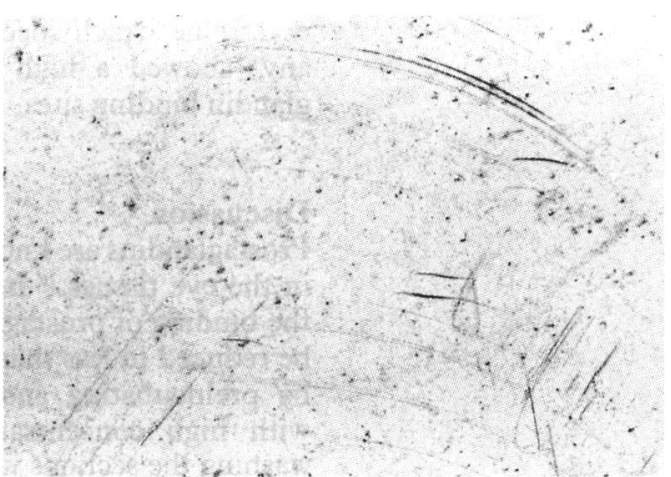

Fig $1 D$

Figure 1 Autoradiographic views of prostaglandin $F_{2 \alpha}$ binding sites in eye sections from a 60 -year-old man. The binding of $20 \mathrm{nM}$ tritiated prostaglandin $F_{2 \alpha}(A)$ concentrates in the ciliary muscle, iris sphincter muscle, iris epithelium, and the retina (and the detached retina). The binding was completely displaced by $100 \mu M$ unlabelled prostaglandin $E_{2}(B)$ and by $100 \mu M$ unlabelled prostaglandin $F_{2 \alpha}(D)$. A Nissl-stained view of $A$ is given in $C$.

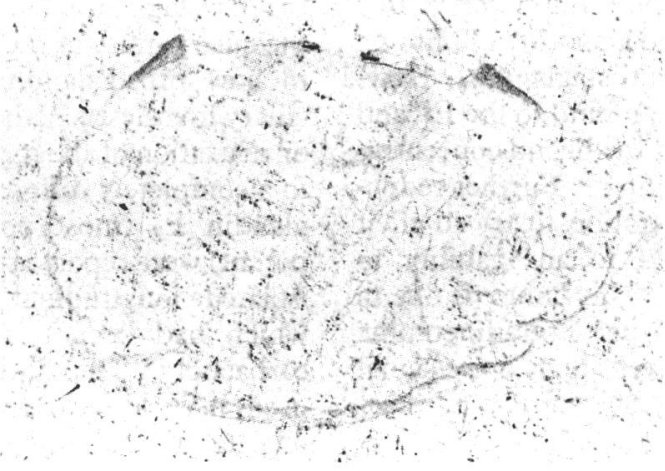

Fig $2 A$

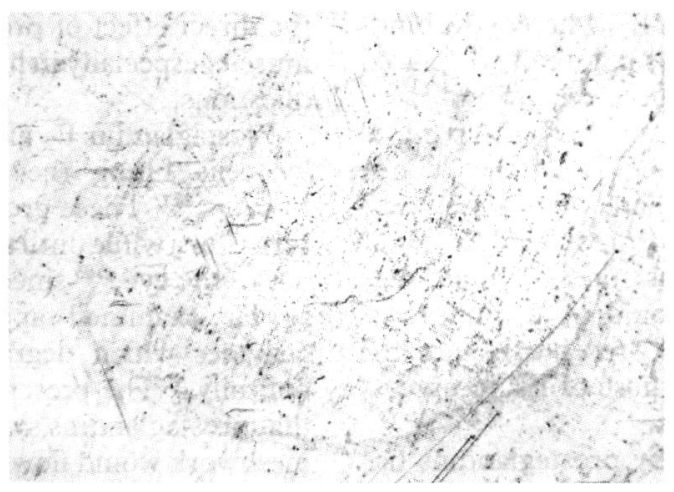

Fig $2 B$

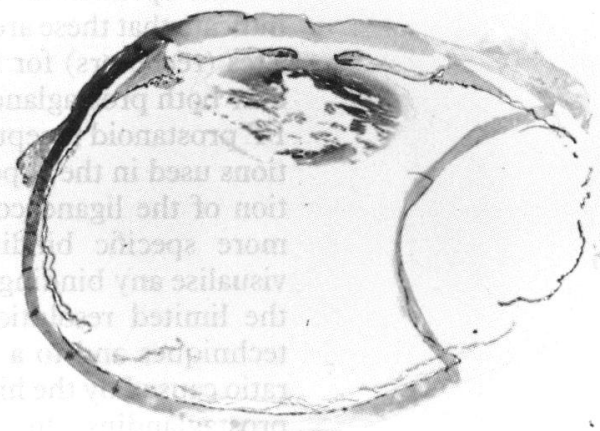

Fig 2C

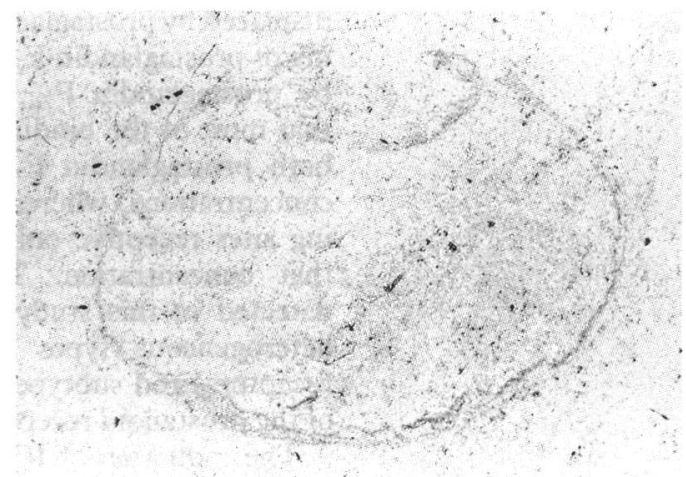

Fig $2 D$

Figure 2 Autoradiographic views of prostaglandin $E_{2}$ binding sites in eye sections from a 60-year-old man. The binding of $20 \mathrm{nM}$ tritiated prostaglandin $E_{2}(A)$ concentrates in the ciliary muscle, iris sphincter muscle, iris epithelium, and the retina (and the detached retina). The binding was completely displaced by $100 \mu \mathrm{M}$ unlabelled prostaglandin $E_{2}(B)$, and partially displaced by $100 \mu M$ unlabelled prostagladin $F_{2 \alpha}(D)$. A Nissl stained view of $A$ is given in $C$. 
$100 \mu \mathrm{M}$ unlabelled prostaglandin $\mathrm{F}_{2 \alpha}$ and prostaglandin $E_{2}$ as shown in Figure 1. The binding of $20 \mathrm{nM}$ tritiated prostaglandin $\mathrm{E}_{2}$ could be totally displaced by $100 \mu \mathrm{M}$ unlabelled prostaglandin $E_{2}$, and partially and evenly in every area by $100 \mu \mathrm{M}$ prostaglandin $F_{2 \alpha}$ as shown in Figure 2.

Retinal detachment commonly resulted during the processing of the eyes of autoradiography. This separated the retina from other layers in the posterior segment and made it clear that specific binding sites for prostaglandin $F_{2 \alpha}$ and $E_{2}$ in the posterior segment were located mainly in the retina with minimal density in the choroid and retinal pigment epithelial cells. The resolution of the autoradiographic films was insufficient to determine which specific layer in the retina, if any, showed a high concentration of prostaglandin binding sites.

\section{Discussion}

Prostaglandins are known to bind with pigments in the eye tissues. ${ }^{16}$ In the present experiments the binding of prostaglandins to pigments could be reduced to less than $10 \%$ of the total binding by preincubating and incubating the sections with high concentrations (5\%) of BSA and washing the sections with $1 \%$ BSA for durations as long as 60 minutes. The conditions used are based on the fact that prostaglandins are lipophilic and bind to the pigments with a weaker affinity than they do to their receptors.

In the present experiments, binding sites for prostaglandin $\mathrm{F}_{2 \alpha}$ and prostaglandin $\mathrm{E}_{2}$ were colocalised to the same areas of the eye, primarily the ciliary muscles and iris sphincter muscles, the iris epithelium, and the retina. The results indicate that these areas had a mixture of binding sites (receptors) for both prostaglandins. However both prostaglandins can bind to the EP and FP prostanoid receptors at the ligand concentrations used in the experiments. ${ }^{6-11}$ Further reduction of the ligand concentration to try to elicit more specific binding led to an inability to visualise any binding sites. This failure is due to the limited resolution of the autoradiographic techniques and to a relatively high noise/signal ratio caused by the high 'background' binding of prostaglandins to the ocular pigments as mentioned above.

The binding of prostaglandin $\mathrm{F}_{2 \alpha}$ was totally displaced by prostaglandin $E_{2}$, whereas the binding of prostaglandin $E_{2}$ was not totally displaced by prostaglandin $F_{2 \alpha}$. These results indicated that most of the binding sites were receptive to both prostaglandin $F_{2 \alpha}$ and $E_{2}$ at the $20 \mathrm{nM}$ concentrations, whereas there were some binding sites receptive only to prostaglandin $E_{2}$ at that concentration. Thus the binding sites detected in this study would be a mixture of heterogeneous types (EP receptors and FP receptors) and subtypes (those of EP receptors) of the prostanoid receptors.

The reduction of IOP by prostaglandins has been previously demonstrated to be mediated by stimulation of the $\mathrm{EP}_{3}$ prostanoid receptor but not of the FP receptor in rabbits. ${ }^{10}$ "It is still unknown which specific class of prostanoid receptors is involved in the pressure reduction induced by prostaglandin $\mathrm{F}_{2 \alpha}$ in human eyes. The present experiments suggest that the ciliary muscles in human eyes have both EP receptors and FP receptors. Further studies using more specific and sensitive ligands not presently available are required to answer the question of which specific class of prostanoid receptors plays the most important role in ocular hypotension.

Prostaglandin $\mathrm{F}_{2 \alpha}$ did not change the production of aqueous humour by the ciliary epithelial cells, ${ }^{17}{ }^{18}$ nor did it facilitate conventional outflow through the trabecular meshwork in humans ${ }^{417}$ or monkeys. ${ }^{19}$ Instead prostaglandin $F_{2 \alpha}$ apparently enhanced uveoscleral outflow in monkeys ${ }^{1213}$ and its pressure-lowering effect was antagonised by pilocarpine. ${ }^{14}$ However the exact mechanism by which it modulates the uveoscleral outflow remains unknown. Uveoscleral outflow can be affected by the tone of the ciliary muscles: contraction of the muscles induced by pilocarpine reduces the uveoscleral flow whereas their relaxation by atropine enhances the flow. ${ }^{2021}$ The binding sites for prostaglandin $F_{2 \alpha}$ appeared to be localised along bundles of the ciliary muscle in the ciliary body. It is therefore most probable that receptors for prostaglandin $F_{2 a}$ are located on the ciliary muscles.

Repeated doses of prostaglandin $\mathrm{F}_{2 \alpha}$ produced narrowing of the ciliary muscle fibres and widening of the intermuscular spaces in cynomolgus monkeys ${ }^{22}$ and might also cause lysis and loss of intermuscular connective tissue. ${ }^{23}$ Its administration was accompanied by partial reversal of resting myopia in monkeys ${ }^{2+}$ but it did not induce any measurable refractive changes in humans. ${ }^{3+}$

Although the facts mentioned above suggest that prostaglandin $F_{2 \alpha}$ could induce relaxation of the ciliary muscles there has been no evidence as to how prostaglandins would act directly on ciliary muscles, whether they induce contraction or relaxation of the muscles, or whether they act in a completely different way. Recently, prostaglandin $E_{2}$ (most potent), $D_{2}$ and $F_{2 a}$ (less potent) were reported to induce relaxation of the isolated longitudinal ciliary muscles of cats which had been contracted beforehand with carbachol. ${ }^{25}$ The autoradiographic techniques used here also demonstrated that the ciliary muscle in cats had binding sites for prostaglandin $F_{2 \alpha}$ and $E_{2}$ as did in humans (data not shown). It will be necessary to examine further the direct effect of prostaglandins on the ciliary muscle, especially in humans, to fully solve these questions.

Prostaglandin $\mathrm{E}_{2}$ and $\mathrm{F}_{2 \alpha}$ can be synthesised by cells lining the trabecular meshwork in humans. ${ }^{26} 27$ These prostaglandins would remain active for a while until they flow or are transported out of the eye, ${ }^{28} 29$ since ocular tissues in humans so far examined apparently do not contain enzymes which degrade prostaglandins metabolically. ${ }^{30}$ The present results support the idea that prostaglandins synthesised in the trabecular meshwork would flow posteriorly in the aqueous humour and reach the ciliary body where they may modulate uveoscleral outflow consequent to binding to their receptors located on the ciliary muscle. Of course there is another possibility, namely, that the ciliary muscle itself might 
synthesise prostaglandins under certain conditions and thus might, in effect, turn on the uveoscleral outflow pathway.

The fact that the iris sphincter muscles had binding sites for prostaglandin $F_{2 \alpha}$ and $E_{2}$ suggests that both prostaglandins might induce miosis although miosis caused by their topical administration has not yet been confirmed clinically. ${ }^{31}$

Prostaglandins play a role in the development of cystoid macular oedema especially after cataract extraction. ${ }^{32}$ Binding sites for prostaglandin $F_{2 \alpha}$ and $E_{2}$ found in the retina might support the role of these compounds in cystoid macular oedema. Prostaglandins are known to be actively transported out of the intraocular fluids by an organic acid transport system located in the ciliary epithelium and retinal capillaries. ${ }^{28} 29$ Therefore there is a possibility that some of the binding sites detected in the retina by the ligandbinding method would be the sites of this transporter. This result also suggests a possibility that prostaglandin $\mathrm{F}_{2 \alpha}$ and $\mathrm{E}_{2}$ could play roles as retinal neuromodulators as has been shown in the brain..$^{33}$

Receptor proteins for prostaglandin $\mathrm{E}_{2}$ and $F_{2 \alpha}$ have been solubilised and shown to be coupled with guanine nucleotide binding proteins ( $G$ proteins). ${ }^{34}$ Recently a gene for the human thromboxane $A_{2}$ receptor has been cloned and shown to belong to the superfamily of $\mathrm{G}$ protein-coupled receptor proteins. Expression of this cloned gene for thromboxane $A_{2}$ revealed that the receptor responded only to thromboxane $A_{2}$ agonists but not to prostaglandin $D_{2}$ or $F_{2 \alpha}$, supporting the working hypothesis that there might be a separate receptor for each of the naturally occurring prostanoids. In the future molecular biological approaches will further enhance our understanding of the action of prostaglandins in ocular tissues.

This work was supported by a MRC fellowship to TM and by grants from Allergan Pharmaceutical Co Ltd, Irvine, CA, USA.

1 Giuffre G. The effects of prostaglandin F2alpha in the human eye. Graefes Arch Cin Exp Ophthalmol 1985; 222: 139-41.

2 Lee PY, Shao H, Xu L, Qu CK. The effect of prostaglandin F2alpha on intraocular pressure in normotensive human subjects. Invest Ophthalmol Vis Sci 1988; 29: 1474-7.

3 Villumsen J, Alm A. Prostaglandin F2alpha-isopropylester eye drops: effects

4 Camras CB, Siebold EC, Lustgarten JS, et al. Maintained reduction of intraocular pressure by prostaglandin F2alphal-isopropyl ester applied in multiple doses in ocular hyper1-isopropyl ester applied in multiple doses in ocular hypertensive and

5 Villumsen J, Alm A, Soederstroem M. Prostaglandin F2alphaisopropylester eye drops: effect on intraocular pressure in open-angle glaucoma. Br $\mathcal{F}$ Ophthalmol 1989; 73: 975-9.

6 Kennedy I, Coleman RA, Humphrey PPA, Levy GP, Lumley $P$. Studies on the characterization of prostanoid receptors: proposed classification. Prostaglandins 1989; 24: 667-89. 7 Coleman RA, Humphrey PPA, Kennedy I, Lumley P. fication. Trends Pharmacol Sci 1984; 5: 303-6.

8 Dong YJ, Jones RL, Wilson NH. Prostaglandin E receptor subtypes in smooth muscle: agonist activities of stable
prostacyclin analogues. $B r \mathcal{F}$ Pharmacol 1986; 87: 97-107.

9 Eglen RM, Whiting RL. Characterization of the prostanoid receptor profile of enprostil and isomers in smooth muscle receptor profile of enprostil and isomers in smooth muscle
and platelets in vitro. Br $\mathcal{F}$ Pharmacol 1989; 98: 1335-43.
10 Woodward DF, Burke JA, Williams LS, Palmer BP, Wheeler LA, Woldemussie F, et al. Prostaglandin F2alpha effects on intraocular pressure negatively correlate with FP-receptor stimulation. Invest Ophthalmol Vis Sci 1989; 30: 1838-42.

11 Waterbury LD, Eglen RM, Faurot GF, Cooper GF. EP3, but not EP2, FP, or TP prostanoid-receptor stimulation may reduce intrac

12 Gabelt BT, Kaufman PL. Prostaglandin F2alpha increases uveoscleral outflow in the cynomolgus monkey. Exp Eye Res 1989; 49: 389-402.

13 Nilsson SFE, Samuelsson M, Bill A, Stjernschantz J: Increased uveoscleral outflow as a possible mechanism of ocular hypotension caused by prostaglandin F2alpha-1isopropylester in the cynomolgus monkey. Exp Eye Res 1989; 48: 707-16.

14 Crawford K, Kaufman PL. Pilocarpine antagonizes prostaglandin F2alpha-induced ocular hypotension in monkeys. Evidence for enhancement of uveoscleral outflow by prostaglandin F2alpha. Arch Ophthalmol 1987; 105: 1112-6.

15 Bito LZ. Species differences in the responses of the eye to irritation and trauma: a hypothesis of divergence in ocular defense mechanisms, and the choice of experimental animals for eye research. Exp Eye Res 1984; 39: 807-29.

16 Aula P, Kaila T, Huupponen R, Salminen L, Iisalo E Prostaglandin F2alpha binding to bovine ocular and synthetic Prostaglandin F2alpha binding to bovine ocular and sy
melanins in vitro. Pharmacol Toxicol 1989; 65: 100-3.

17 Kerstetter JR, Brubaker RF, Wilson SE, Kullerstrand LJ. Prostaglandin F2alpha-1-isopropylester lowers intraocular Prostaglandin F2alpha-1-isopropylester lowers intraocular pressure without decreasing

18 Camras CB, Podos SM, Rosenthal JS, Lee PY, Severin CH. Multiple dosing of prostaglandin F2alpha or epinephrine on cynomolgus monkey eyes. 1. Aqueous humor dynamics. Invest Ophthalmol Vis Sci 1987; 28: 463-9.

19 Gabelt BT, Kaufman PL. The effect of prostaglandin F2alpha on trabecular outflow facility in cynomolgus monkeys. $E x p$ Eye Res 1990; 51: 87-91.

20 Bill A. Uveoscleral drainage of aqueous humor in human eyes. Exp Eye Res 1971; 12: 275-81.

21 Bill A. Effects of atropine and pilocarpine on aqueous humo dynamics in cynomolgus monkeys (Macaca irus). Exp Eye Res 1967; 6: 120-5.

22 Luetjen-Drecoll E, Tamm E. Morphological study of the anterior segment of cynomolgus monkey eyes following
treatment with prostaglandin F2alpha. Exp Eye Res 1988; 47: 761-9.

23 Tamm E, Luetjen-Drecoll E, Rittig M, Rohen, JW. Connective tissue changes in the uveoscleral pathways of primate eyes after treatment with prostaglandin F2alpha. ARVO abstracts. Supplement to Invest Ophthalmol Vis Sci. Philadelphia: Lippincott, 1989: 99.

24 Crawford KS, Kaufmann PL. Dose-related effects of prostaglandin F2alpha isopropylester on intraocular pressure,
refraction, and pupildiameter in monkeys. Invest Ophthalmol Vis Sci 1991; 32: 510-9.

25 Chen J, Protzman CE, Woodward DF. Comparison of the pharmacology of prostanoid induced ciliary muscle relaxation and ocular hypotension reveals a correlation. ARVO abstracts. Supplement to Invest Ophthalmol Vis Sci. Philaabstracts. Supplement to Invest
delphia: Lippincott, 1991: 870 .

26 Weinreb RN, Mitchell MD, Polansky JR. Prostaglandin production by human trabecular cells: in vitro inhibition by

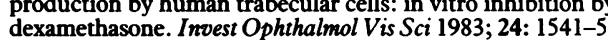

27 Weinreb RN, Polansky JR, Alvarado JA, Mitchell MD Arachidonic acid metabolism in human trabecular mesh work cells. Invest Ophthalmol Vis $S c i$ 1988; 29: 1708-12.

28 Bito LZ, Wallenstein MC. Transport of prostaglandins across the blood-brain and blood-aqueous barriers and the physiological significance of these absorptive transport processes. Exp Eye Res 1977; 25 (suppl): 229-43.

29 Bito LZ. Prostaglandins and other eicosanoids: their ocular transport, pharmacokinetics, and therapeutic effects. Trans Ophthalmol Soc UK 1986; 105: 162-70.

30 Cheng-Bennett A, Poyer J, Weinkam RJ, Woodward DF Lack of prostaglandin F2alpha metabolism by human ocular tissues. Invest Ophthalmol Vis Sci 1990; 31: 1389-93.

31 Miranda OC, Bito LZ. The putative and demonstrated miotic effects of prostaglandins in mammals. In: Bito LZ, miotic effects of prostaglandins in mammals. In: Bito LZ, Stjernschantz J, eds. The ocular effects of prostaglan

32 Miyake $\mathbf{K}$. Prevention of cystoid macular edema after lens extraction by topical indomethacin. I. A preliminary report. Graefes Arch Clin Exp Ophthalmol 1977; 203: 81-8.

33 Watanabe Y, Watanabe Y, Hamada K, Bommelaor-Bayt MC Dray F, Kaneko T, et al. Distinct localization of prostaglandin D2, E2 and F2alpha binding sites in monkey brain Brain Res 1989; 478: 143-8.

34 Halushka PV, Mais DE, Mayeux PR, Morinelli TA. Thromboxane, prostaglandin and leukotriene receptors. Annu $R e v$ Pharmacol Toxicol 1989; 10: 213-39.

35 Hirata M, Hayashi Y, Ushikubi F, Yokota Y, Kageyama R, Nakanishi S, et al. Cloning and expression of cDNA for a human thromboxane A2 receptor. Nature 1991; 349: human 